\title{
A relação entre o escritor e a produção escrita no viés da dialogicidade e interatividade
}

The relationship between the writer and written production in the

Exchange and interactivity

Ilsa do Carmo Vieira Goulart

Universidade Federal de Lavras

Resumo:Este artigo considera que as palavras escritas se inserem em uma relação dialógica marcada pela complexidade dos enunciados, visto que a produção escrita decorreu de um processo de apreensão, de interação entre o escritor e ação de escrever, que se configurou em um determinado tempo e espaço. Diante disso, assume-se por objetivo refletir e analisar como alguns poetas expressam sua relação com a atividade de produção escrita, descrita e demarcada na expressividade de seus textos. $O$ trabalho apoia-se na concepção de linguagem como processo de interação de Bakhtin, em interlocução com outros autores. 0 estudo toma como corpus investigativo textos como poemas, prosas poéticas de diferentes autores, selecionados por demarcarem em sua produção escrita uma ideia ou uma representação da conceituação do ato de escrever.

Palavras-chave: Linguagem escrita. Produção de sentidos. Dialogismo.

Abstract:This article considers that written words are in a dialogical relationship marked by the complexity of the listed, since the written work stems from a process of apprehension, of interaction between the writer and write action, if you have set up in particular time and space. Given this, it is assumed the purpose reflectand analyze how some poets express their relationship with writing production activity, described and marked on the expressiveness of their texts. The work is based on language design as a process of interaction of Bakhtin, in dialogue with other authors. The study takes as investigative corpus texts such as poetry, poetic prose of different authors, selected by classified in your written work an idea or a representation of the conceptualization of the act of writing.

Keywords: Written language. Production of senses. Dialogism. 


\section{Palavras iniciais}

Ilsa do Carmo

Vieira Goulart

160
Razão de ser

Escrevo e pronto.

Escrevo porque preciso,

Preciso porque sou tonto.

Ninguém tem nada com isso.

Escrevo porque amanhece,

e as estrelas lá no céu

lembram letras no papel.

$A$ aranha tece teias.

o peixe beija e morde o que vê.

Eu escrevo apenas.

Tem que ter por que?

Paulo Leminski (2002, p. 135)

$O$ ato de escrever traz em si seus encantos e desafios, uma atividade que move o escritor à sua produção, ora sem uma aparente razão de ser, escreve-se e pronto, conforme a epígrafe, ora escreve-se por necessidade, por urgência, por demanda. o que se sabe é que a escrita se figura em um espaço de produção ativa e criativa da arte, da ciência, do profissionalismo ou do entretenimento. As palavras, concatenadas na individualidade escritora, mostram-se impulsionadas à expressividade, almejam de modo ostensivo o outro, na busca por leitores ávidos, permitem a compreensão e a construção de uma rede de diálogos.

O trabalho parte da concepção de que os sujeitos, em sua especificidade humana, expressam-se por meio da linguagem materializada em textos verbais ou não verbais. Entende-se que o texto verbal, oral ou escrito, constitui-se como enunciado a partir de dois planos: o da intencionalidade e o da sua materialização. A inter-relação e a interlocução entre esses dois planos é que determina a essência da escrita.

o fluxo da produtividade escrita decorre de um movimento dinâmico, ativo e interativo. Longe de ser articulado pela calmaria, passividade ou linearidade, a ação escritora se mostra, muitas vezes, demarcada por tensões, por sentimentos ambíguos de contentamento e descontentamento, de consternação e prazer, de fluididade e truncamentos, de complementariedade e incompletude. Por se constituir de movimentos precisos e imprecisos, por ações de ir e vir da ação reflexi- 
va, conforme defendem Val e Vieira (2005, p. 38), o processo de produção textual pode ser considerado como "[...] atividade discursiva”.

Nesta perspectiva, o trabalho tem por finalidade analisar como alguns escritores expressam sua relação com a atividade de produção escrita, descrita e demarcada na expressividade de seus textos, com intuito de refletir e compreender como este sujeito-escritor externaliza sua relação com o ato de escrever, balizando ideias e representações aos sentidos produzidos por este processo dialógico.

$\mathrm{Na}$ tentativa de compreender sobre os sentidos agregados à expressividade da palavra, como linguagem escrita, o trabalho encontra-se uma proximidade aos estudos de Goulart (2012), ao sinalizar que a produção textual incide na complexidade de uma rede de ações e relações. Isso ocorre seja por se apresentar entrelaçada à obscuridade, ou A relação entre o escritore a produção escrita no viés da dialogicidade einteratividade melhor, à imprecisão das ideias, à flexibilidade estética do enredo criativo, relacionado à estrutura composicional do texto e à singularidade do sujeito que articula a produção escrita, seu estilo, seja por esbarrar na dimensão da inter-relação entre o autor e o ato de escrever, rústica ou fluida, seja por estar subordinada às condições de externas, físicas, emocionais, temporais, situacionais.

Deste modo, o trabalho discorrerá sobre a linguagem como ação discursiva, tomando como corpus investigativo textos, como poemas e prosas poéticas de diferentes escritores, selecionados por demarcarem em sua escrita uma ideia ou uma representação da conceituação da palavra, entendida em sua concepção mais ampla da linguagem. A análise apoia-se na concepção de interdiscursiva da linguagem apoiada em Bakhtin (2003, 2006, 2008, 2010), em interlocução com outros autores, numa tentativa de compreensão do enredamento que envolve o processo de interação entre escritor e sua produção escrita.

Ao assumir como objeto de estudo excertos de poemas e prosas, a pesquisa insere-se em uma relação dialógica marcada pela complexidade dos enunciados, visto que se direciona para a compreensão de um momento passado em que ocorrera a relação entre escritor e a produção escrita. Esta relação espaço-tempo permite uma aproximação de ideia cronotopo e exotopia de Bakhtin (2003), que segundo Amorim (2012, p.98), são conceitos significativos para as Ciências Humanas. Entendendo que o homem, por ser um sujeito falante, produz textos e cria diálogos, a intenção da pesquisa não é emudecer o texto dos escritores ou minimizar os sentidos produzidos pelos excertos selecionados, mas 
Ilsa do Carmo

Vieira Goulart

“[...] restituir as condições de enunciação e de circulação que lhe conferem as múltiplas possibilidades de sentido".

Por saber que "[...] toda palavra dialoga com outras palavras", conforme Fiorin (2006, p.19), procura-se entender o que diferentes escritores disseram sobre a própria relação com a palavra, tendo em vista que a ação de escrever decorreu de processo dialógico com outros textos. A interdiscursividade requer um espaço de articulação entre o escrito, mas também entre o imaginável, pelo que se pode ser inferido a partir da produção de sentidos do leitor-pesquisador.

Desta forma, procurou-se em um momento inicial discorrer sobre a palavra, entendida, aqui, não apenas como a expressão e materialização de uma ideia, mas como linguagem, como uma prática social que produz sentidos, que constrói e cria outros enunciados a partir de uma determinada realidade, pensada e articulada pelo autor, bem como organizada e impressa pelo editor. Para em seguida, apresentar os excertos de poemas e prosas selecionados, na ousadia de uma reflexão dialógica a partir de representações expressas em versos e palavras sobre $o$ ato de escrever.

\section{A palavra, como linguagem: em busca de uma definição}

A palavra, longe de ser representada apenas como um vocábulo desconexo do contexto discursivo, aparece representada por Bakhtin (2006) como um processo de articulação da própria linguagem, concretizada em enunciados e delimitada pelo "colorido expressivo" da significação.

De acordo com os estudos de Stella (2013), a palavra para Bakhtin pode ser compreendida e definida sob quatro propriedades: a pureza semiótica, a possibilidade de interiorização, a participação em todo ato consciente e a neutralidade.

Stella (2013), ao descrever cada característica, explicita que a pureza semiótica corresponde à capacidade de funcionamento e circulação como signo ideológico; a interiorização, trata-se do veículo de articulação entre a consciência interior e mundo exterior construído pelas palavras, pois a “[...] consciência individual não é o arquiteto dessa superestrutura ideológica, mas apenas um inquilino do edifício social dos signos ideológicos" (BAKHTIN, 2006, p. 34).

A compreensão de participação em todo ato consciente refere-se à ideia de que a palavra funciona tanto nos processos interiores da consciência, no modo de compreensão e interpretação do mundo pelo 
sujeito, quanto nos processos exteriores, nos modos de circulação e materialização das palavras na diversidade das dimensões ideológicas. A neutralidade da palavra, por ser considerada um signo ideológico, torna-se neutra em qualquer função ideológica específica, por assumir qualquer função ideológica, seja estética, científica, moral ou religiosa. (BAKHTIN, 2006, p. 34).

A palavra, na inteireza enunciativa, não se configura pelo pertencimento a alguém, mas pelo desprendimento autoral, descrito por Bakhtin (2003, p. 289) como sem autoria, pois “[...] é de ninguém, como a palavra, e só funcionando como enunciado pleno ela se torna expressão da posição do falante individual em situação concreta de comunicação discursiva".

Ao incorporarmos as palavras do outro em nosso discurso, asA relação entre o escritore aprodução escrita no viés da dialogicidade einteratividade sumimos a autoria do enunciado, o que a concepção do dialogismo nos mostra, porque todo o enunciado é constituído a partir de outros. 0 discurso do outro perpassa a construção do meu discurso, torna-se o elo na rede da comunicação discursiva, de modo que a palavra se articula a outras tantas palavras, em que o sujeito (falante, escritor ou leitor) assume uma posição ativa na articulação no campo do objeto, na forma de concretização da palavra e no campo da produção de sentidos.

A palavra escrita, como enunciado, apresenta um elemento expressivo que determina sua composição e estilo. Para Bakhtin (2003, p. 289), é a relação valorativa entre o falante e o objeto do seu discurso, da composição do seu conteúdo a ser exposto, que determina a escolha de recurso lexical, gramatical e composicional, o que caracteriza a individualidade enunciativa, atribuindo-lhe um aspecto expressivo.

\footnotetext{
Quando escolhemos as palavras, partimos do conjunto projetado do enunciado, e esse conjunto que projetamos e criamos é sempre expressivo e é ele que irradia sua expressão (ou melhor, a nossa expressão) a cada palavra que escolhemos; por assim dizer, contagia essa palavra com a expressão do conjunto. E escolhemos a palavra pelo significado que em si mesmo não é expressivo, mas pode ou não corresponder aos nossos objetivos expressivos em face de outras palavras, isto é, em face do conjunto do nosso enunciado. (BAKHTIN, 2003, p. 292)
} 
Ilsa do Carmo

Vieira Goulart

164

Se consideramos a palavra como um conjunto enunciativo, demarcado pela expressividade, o ato de escolha não pode ser aleatório ou incidental, mas pensado, planejado e articulado na determinação e escalação do léxico, da estrutura gramatical ou composicional, que constituirá a textualidade, oral ou escrita. $O$ texto aparece envolto pelas relações de sentido entre o sujeito e as palavras, e sua composição se efetiva numa interação discursiva, definida pela função ativa entre sujeito e palavra no processo de produção textual.

Ao estudar sobre a relação entre o autor e sua produção escrita, Goulart (2012) procura descrever a compreensão de palavra como expressão da linguagem da escrita, a partir da composição de diferentes autores da literatura. Assim, a autora observa que a palavra se articula em representações caracterizadas e descritas em três aspectos: o primeiro como objeto dormente, em que a palavra é percebida e descrita como um elemento inerte, como algo ou um ser inanimado, mas que pode recuperar a vivacidade pela ação e atuação do autor ou do leitor ao utilizá-la, seja no ato da leitura ou no ato da escrita.

Outro aspecto aparece como um objeto misterioso, como "coisa" indefinida, inacessível, inatingível, que provoca interesse e curiosidade por conter algo de místico, o que leva os autores a denominá-la "coisa", como na descrição de Sartre (2004, p. 16) - as “[...] palavras-coisas agrupam-se por associações mágicas de conveniência ou desconveniência, como cores e sons, atraem-se e se repelem, queimam-se, e sua associação compõe a verdadeira unidade poética que é a frase-objeto". Tal característica, segundo Goulart (2012), configura-se sem a intenção de redução da palavra a um simples objeto, mas de ampliação do seu significado. Ao relacionar a palavra à "coisa", pode-se pensar na ação escritora como algo indecifrável, como descrita nos versos de Quintana (1989, p. 88): “A gente pensa uma coisa, acaba escrevendo outra e o leitor entende uma terceira coisa..."

A terceira categorização da palavra mostra-se como um objeto em construção pela ação do autor, que parece materializar-se longe da passividade, visto que decorre da interatividade e da inventividade, num processo interdiscursivo de composição textual. Goulart (2012) descreve este momento a partir de três etapas: a que antecede, a que segue e a que finaliza a produção textual. A que antecede caracteriza-se pelas escolhas e possibilidades que o escritor tem ou terá na efetuação da composição, pela tensão entre o que se pretende escrever e o como 
se efetivará tal escrita. A que segue surge no ato da interatividade, na produção, uma ação que se destaca pelo envolvimento de um trabalho incansável de (re)construção, de (re)elaboração; distingue-se por um fazer, refazer, desfazer até a obtenção de matéria bruta. Na finalização, após um árduo processo de produção, de poética, o texto acabado ganha outro lugar, não pertencente ao autor, uma "prática da perda da palavra", nos diria Certeau (2007, p. 298). O texto ganha movimento próprio, torna-se espaço alheio, espaço de concretização ou materialização das palavras em um dado suporte (impresso ou digital), em que se executa uma "operação de caça", segundo Certeau (2007), ao sentido através da leitura.

Ao delinear facetas da relação que o autor estabelece com e sobre a sua produção escrita, Goulart (2012) aponta duas questões

A relação entre o escritore a produção escrita no viés da dialogicidade einteratividade que marcam esta proximidade com as palavras: uma sinaliza que o relacionamento autor-texto se mostra permeado de representações para tentar defini-la e compreendê-la; outra indica que as palavras consolidam-se pelas ações e interações, sejam estas do autor ou do leitor, numa atividade de construção e de produção incansável de sentidos.

A relação entre o autor-escritor ou autor-leitor e as palavras envolve-se, circunda-se de ações, atuações e indagações, seja pelas representações que elas produzem, seja pelo processo de interação em que elas estão inseridas. $O$ que se sabe é que as palavras se fazem presentes em todas as circunstâncias vivenciadas e experienciadas pelos sujeitos, pois conforme Bakhtin (2010, p. 35) descreve "[...] o material privilegiado da comunicação na vida cotidiana é a palavra".

Para Bakhtin (2006, p.30), adjacente ao universo de fenômenos naturais que acercam a vida cotidiana, existe um universo particular, "o universo de signos". Os signos não se constituem apenas como um fragmento do real, mas, para o autor, pode ser um reflexo de outra realidade, apresentada de modo similar, distorcido ou demarcando fidelidade ao demonstrá-la de um ponto de vista específico, entre outras possibilidades. Isso porque submete-se aos critérios de avaliação ideológica, em que há uma correspondência entre signo e ideologia, visto que "[...] o domínio do ideológico coincide com o domínio dos signos: são mutuamente correspondentes. Ali onde o signo se encontra, encontra-se também o ideológico. Tudo que é ideológico possui um valor semiótico" (BAKHTIN, 2006, p.30). 
Ilsa do Carmo

Vieira Goulart

Este valor semiótico mostra-se expressivamente de maneira mais inteira e intensa na linguagem. A palavra torna-se a representação da realidade de um processo de interação social, por ser considerada "[...] o fenômeno ideológico por excelência", de acordo com Bakhtin (2006, p. 34), traz a potência da função de signo, por ser um modo mais sensível e íntegro de relação social.

A palavra, segundo Bakhtin (2006, p. 35), um signo linguístico resultante de uma convenção social, pode ser compreendida como trabalho de expressão em dimensões tanto na esfera interpessoal das relações, quanto na esfera intrapessoal, visto que

\footnotetext{
Embora a realidade da palavra, como a de qualquer signo, resulte do consenso entre os indivíduos, uma palavra é, ao mesmo tempo, produzida pelos próprios meios do organismo individual, sem nenhum recurso a uma aparelhagem qualquer ou a alguma outra espécie de material extracorporal. Isso determinou o papel da palavra como material semiótico da vida interior, da consciência (discurso interior).
}

É por desempenhar esta função excepcional de instrumento da consciência que a palavra funciona como elemento essencial que acompanha toda criação ideológica, seja ela qual for, na oralidade, na escrita, por meio da música, da arte, da dança, dos gestos, entre outras, possibilita ao sujeito expressar-se, colocar-se diante do mundo com suas ideias, sua identidade, suas características próprias (BAKHTIN, 2006).

Ao elaborar um estudo sobre a palavra na perspectiva bakhtiniana, Stella (2013, p.178) aponta que, além de estar relacionada à vida, a palavra parte de um processo de interação entre o falante e interlocutor, traz uma concentração de entonações, entendida como valores atribuídos a uma avaliação ideológica do locutor sobre aquilo que está emitindo. Este valor corresponde a uma avaliação feita pelo locutor diante da ação responsiva de seu interlocutor, haja vista que "[...] o falante, ao dar vida à palavra com sua entonação, dialoga diretamente com valores da sociedade, expressando seu ponto de vista em relação a estes valores".

À palavra escrita parece ser atribuído um valor social por estar presente em todos os atos de relações sociais, de compreensão, de significação, pois, para Bakhtin (2012, p. 116), “[...] o que faz da palavra uma palavra é sua significação". Coexiste a partir do significado a ela 
atribuído, um movimento intenso de produção de sentidos, como no poema Palavra, de Falcão (2003), em que diz “[...] toda palavra tem a cara do seu significado", assim a palavra sem seu significado torna-se estranha, nada diz, pois resume-se apenas a letra e som.

\section{A produção escrita compreendida em relações dialógicas} Considerando que toda palavra comporta duas dimensões, daquele que

A relação entre o escritore a produção escrita no viés da dialogicidade einteratividade para o sujeito (falante ou escrevente) em três aspectos: como decorrente da língua, o que lhe atribui o caráter de ser pertencente a ninguém, mas de uso comum de todos; como alheia dos outros, repletas de ecos enunciativos; como minha, que se caracteriza pela possibilidade do sujeito de utilizá-la em uma determinada situação, de um determinado modo, o que lhe confere uma expressão particularizada, como propriedade do sujeito.

Se a palavra possibilita a interação entre eu e o mundo, estabelece-se aqui a interação entre a atividade de leitura e a palavra escrita, ao descrever representações sobre o ato de escrever. Por isso, entendendo que a análise apresentada corresponde a um processo de interlocução entre a ação leitora de uma pesquisadora e a produção escrita dos autores, procura-se redesenhar o "colorido expressivo" que, segundo Bakhtin (2003, p. 295), só se obtém no enunciado.

No diálogo com as palavras produzidas em poemas e prosas poéticas, em dado tempo e espaço, pertencentes a escritores consagrados pela produção literária, procura-se descrever as relações construídas entre o autor e a palavra escrita. Cada enunciado escolhido se mostra repleto de experiência discursiva individual, com esforço de ser um espaço significativo de interlocução, pois, para Bakhtin (2003, p. 295), a palavra "[...] carece de expressividade". Diante disso, busca-se num movimento de aproximação entre excertos de poemas e prosas, em que se observa demarcações nos escritos de ações dialógicas que configuram representações sobre o ato de escrever, classificadas aqui como relações de complementariedade, de enamoramento e de conflitos e embates. 
Ilsa do Carmo

Vieira Goulart

168

\section{Relação de complementariedade}

Neste modo característico de ação dialógica, o relacionamento com palavra escrita torna-se um recurso de expressividade. Frente à incompletude e à complexidade de expressar sentimentos, inquietudes e anseios, a palavra escrita é vista com um recurso auxiliador ao sujeito para apregoar seus interesses, ideias, sentimentos, concepções, limitadas pela oralidade. Por exemplo, Manuel de Barros (2010, s/p), em $O$ apanhador de desperdícios, parece descrever uma relação entre o escritor e as palavras cercada pelo ato de complementariedade de ações.

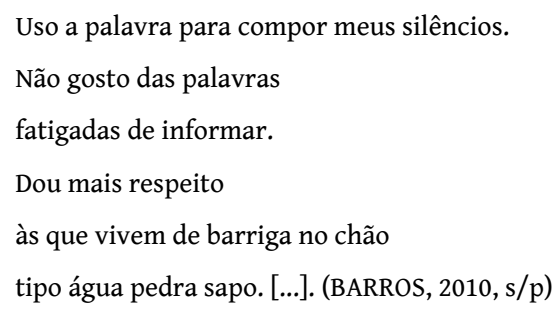

No enunciado "uso palavras para compor meus silêncios", primeiro pode-se destacar a palavra compor, como indicativo de composição, criação, mas que pode indicar a ideia de arranjo ou endireitamento, a forma como os elementos se agrupam e integram formando um todo; outra palavra silêncios, que utilizada no plural, indica a pluralidade de falas interiores, que no estado de não falar, representa também uma forma de linguagem. A relação entre o eu-lírico-escritor e a atividade de produção textual parece se constituir pela cumplicidade e interdependência. A afinidade com as palavras permite maior expressividade na escrita, pois compreende sua interioridade. Tal intimidade aparece sinalizada em outro poema, Retrato do artista quando coisa:

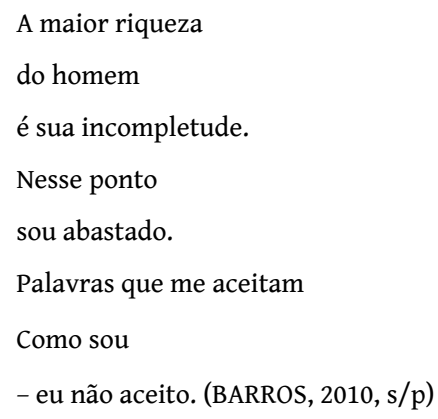


O eu-lírico parece sofrer as angústias da incompletude humana, de um relacionamento intrincado e áspero da expressividade, da sensação de insatisfação que impulsiona o homem em busca da realização de seus anseios. Sofre um dilema em que se tem o sujeito que opera no ofício da produção escrita, mas que se encontra desarticulado da oratória, da articulação e da exposição verbal do que pensa, sente ou deseja. Por isso, busca a complementariedade na concatenação de palavras, na ação dialógica da produção textual.

A palavra escrita se mostra um ato dialógico, primeiro pelo fato de se materializar em discurso, possui um autor, um criador do enunciado, no caso em versos expressos pelo poeta; em segundo, por considerar que as relações dialógicas, segundo Bakhtin (2008, p. 211), “[...] são possíveis também com sua própria enunciação como um todo, com

A relação entre o escritore aprodução escrita no viés da dialogicidade einteratividade partes isoladas deste todo e com uma palavra isolada nele". Ou seja, por representar uma ação dialógica do escritor consigo mesmo, visto que escrever remete a um ato que afeta o próprio escritor.

O que parece se aproximar da compreensão de Barthes (2004, p. 22) sobre o ato de escrever como "diátese", dita pela gramática como as vozes verbais, entende que “[...] escrever é hoje fazer-se o centro do processo de palavra, é efetuar a escritura afetando-se a si próprio, é fazer coincidir a ação e o afeto, é deixar o escritor no interior da escritura".

Escrever poderia se definir como uma ação reflexiva em que se faz e se recebe a ação ao mesmo tempo. Ao produzir enunciados, o escritor é também afetado por eles, pois as palavras não são objetos, mas uma forma ativa e mutável de comunicação dialógica, como descreve Bakhtin (2008).

\section{Relação de enamoramento}

Outra relação estabelecida entre o escritor e a palavra escrita, é aqui denominada de enamoramento, que emerge da configuração marcada pelo encantamento do sujeito-escritor pelas palavras, num ato de se deixar envolver por algo sedutor. A palavra escrita parece fascinar o escritor por se mostrar inatingível, inalcançável, por possuir uma capacidade inovadora, mutável, flexível, visto que em cada enunciado tem-se a possibilidade de criação de um novo sentido, o que provoca sentimentos inusitados, inebriantes e atraentes ao escritor. 
Ilsa do Carmo

Vieira Goulart

[...] Sim Senhor, tudo o que queira, mas são as palavras as que cantam, as que sobem e baixam... Prosterno-me diante delas... Amo-as, uno-me a elas, persigo-as, mordo-as, derreto-as... Amo tanto as palavras... As inesperadas... As que avidamente a gente espera, espreita até que de repente caem... Vocábulos amados... Brilham como pedras coloridas, saltam como peixes de prata, são espuma, fio, metal, orvalho... Persigo algumas palavras... São tão belas que quero colocá-las todas em meu poema... Agarro-as no voo, quando vão zumbindo, e capturo-as, limpo-as, aparo-as, preparo-me diante do prato, sinto-as cristalinas, vibrantes, ebúrneas, vegetais, oleosas, como frutas, como algas, como ágatas, como azeitonas... (NERUDA, 1978, p. 51)

Ao escrever sobre a relação entre o eu-lírico-escritor e as palavras, as expressões "amo-as", "uno-me a elas", "mordo-as", "derreto-as", indicam uma ideia de um sujeito apaixonado, desejante de tê-las consigo, de dominá-las, de se apropriar delas. É uma relação em que a palavra parece assumir a figuração do corpo erótico, como descreve Barthes (2006, p. 66); o texto que é capaz de seduzir o leitor pela sua estruturação e configuração gráfica, pelo modo como se articulam as palavras, insinua-se, antes, ao escritor, em dança envolvente, lança seus encantamentos, desperta desejos insanos, de apreendê-las no texto.

A palavra parece encantar pela sua amplitude de significados, inebria o escritor pela capacidade de assumir a imagem verbal desejada, percebida como o próprio "signo ideológico" que Bakhtin (2006, p. 32) apresenta, explicitando que a consciência irá adquirir sua forma e existência por meio dos signos criados por um grupo organizado no curso de suas relações sociais, visto que "[...] são o alimento da consciência individual, a matéria de seu desenvolvimento, e ela reflete sua lógica e suas leis".

\footnotetext{
E então as revolvo, agito-as, bebo-as, sugo-as, trituro-as, adorno-as, liberto-as... Deixo-as como estalactites em meu poema; como pedacinhos de madeira polida, como carvão, como restos de naufrágio, presentes da onda... Tudo está na palavra... Uma ideia inteira muda porque uma palavra mudou de lugar ou porque outra se sentou como uma rainha dentro de uma frase que não a esperava e que a obedeceu... (NERUDA, 1978, p. 51)
} 
Ao escrever "Tudo está na palavra", o vocábulo "tudo" indica uma ideia de soberania, de império semântico e instável dos vocábulos, pois, no enunciado seguinte, "uma ideia muda porque uma palavra mudou de lugar", o que remete à representação polissêmica das palavras. A fluidez da produção de sentidos tanto para o escritor quanto para o leitor marca um processo de interação com o léxico e sua significação, construindo signos linguísticos, “[...] pois signos só podem aparecer em um terreno interindividual”, segundo Bakhtin (2006, p. 32).

Nesta perspectiva, pode-se dizer que a sedução pelo ato de escrever revela-se pela fugacidade da palavra, regida na multiplicidade de sentidos, num processo de dialógico entre escritor e significação; isso porque os signos só emergem do processo de interação, entre uma consciência individualizada e uma outra, pois a própria consciência individual está repleta de signos e encontra nos enunciados a possibilidade da expressividade.

\title{
Relação de conflitos e embates
}

A relação entre escritor e escrita não acontece na passividade, mas se articula entre tensões, entre a variabilidade daquilo que se pretende expressar e a impossibilidade de articular o valor semiótico das palavras, de modo a construir enunciados precisos, com a expressividade daquilo que se almeja dizer e do modo como é possível dizer. Andrade (2008, p. 243), no poema $O$ Lutador, parece anunciar tal embate:

\author{
Lutar com palavras \\ é a luta mais vã. \\ Entanto lutamos \\ mal rompe a manhã. \\ São muitas, eu pouco. \\ Algumas, tão fortes \\ como o javali. (ANDRADE, 2008, p. 243)
}

A expressão "lutar" sinaliza uma ação de afrontamento ao ato de escrever, remete a uma ideia de que a escrita nem sempre é movida pela indiferença. A produção textual aparece retratada como uma atividade de esforço intelectual, que requer do autor uma dedicação intensa e extensa, um trabalho de reflexão descontínua e desconexa, por exigir um ir e vir do ato pensante, de pesquisa e estudo, de análise e síntese, por vezes balizada de leituras diversas, que demandam um consumo assoberbado de tempo 
para o ato de ler, reler e escrever, em busca de uma imersão temática.

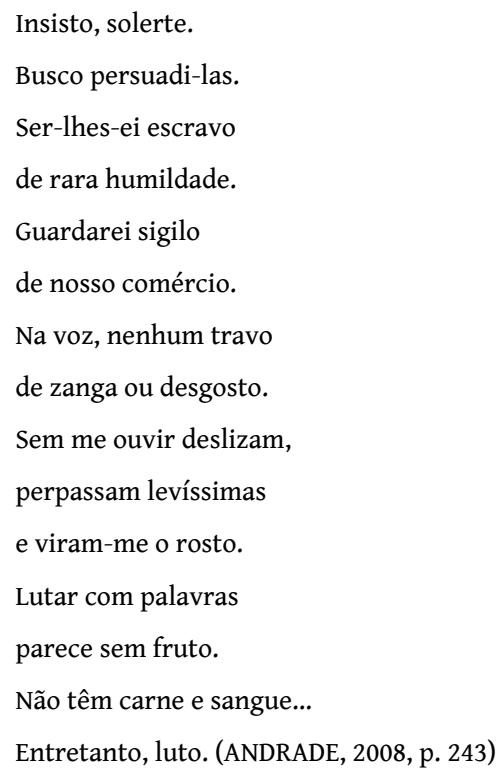

A relação entre escritor e as palavras parece representada pela insistência, pela obstinação de se concretizar o ato, de persuasão do texto, o que consiste em um processo lento e repleto de tensões, pois as palavras escapam, não encontram o sentido para o que se quer expressar. Esta relação configura-se num movimento dialógico, numa atividade de construção ou produção e sentidos, conforme Goulemot (2001), ativa entre o escritor-autor ou escritor-leitor e as palavras, que aparece marcada por escolhas e possibilidades, com vistas à concretização do texto, no que se evidencia o conflito entre o que se pretende escrever e o como se efetivará tal escrita.

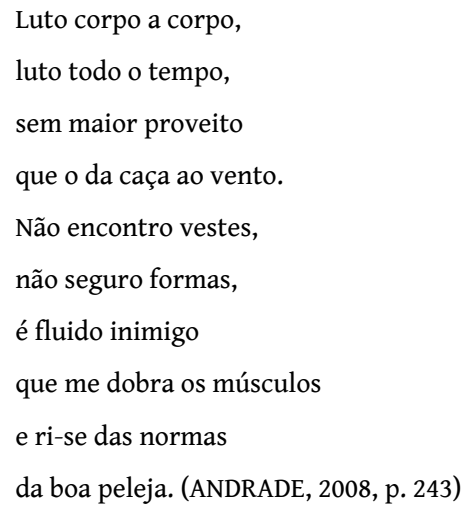


A produção escrita é um trabalho árduo da intelectualidade, que envolve leitura e reflexão. A produção escrita não acontece na passividade, mas num jogo de produtividade e criatividade laborioso, infatigável que transita pelo texto em ações de (re)construção, de (re)elaboração; distingue-se por um fazer, refazer, desfazer para atingir uma forma de expressividade e dialógica.

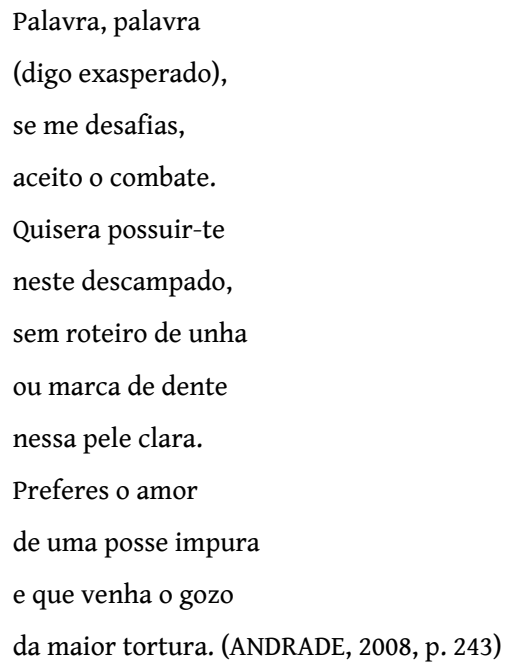

A relação entre o escritore aprodução escrita no viés da dialogicidade einteratividade

O embate travado com a atividade escritora não é o martírio infindável, parece um confronto com as próprias angústias internas do escritor, funciona como uma atividade desafiante na relação com a linguagem escrita, pois “[...] um sapiente amor me ensina a fruir/ de cada palavra/ a essência captada,/ o sutil queixume". (ANDRADE, 2008, p. 243).

$\mathrm{O}$ ato de escrever descrito pelo poeta se mostra uma experiência subjetiva e individualizada, mas Bakhtin (2010, p.125), nos mostra que “[...] o centro organizador de toda enunciação, de toda expressão, não é interior, mas exterior: está situado no meio social que envolve o indivíduo". Neste sentido, entendendo que toda enunciação é produto de uma interação social, o ato de escrever é um processo de interatividade, por retratar ações que não são únicas de um sujeito, mas por retratar uma representação social a respeito do ato de escrever, como habilidade difícil, que é reservada a poucos, que não se configura na linearidade, mas num processo irregular e instável de elaboração de ideias, de interatividade reflexiva com aquilo que se deseja expressar em busca da palavra que melhor poderá representar sentimentos, ideias, conceitos, etc. 
Ilsa do Carmo

Vieira Goulart

\section{Palavras finais}

Este trabalho teve como objetivo refletir sobre a relação construída entre escritor e a atividade de produção escrita, por meio da expressividade das palavras, concretizadas em poemas e prosas, em excertos selecionados por articularem ideias e representações sobre a produção escrita. Ao tecer a reflexão sobre a palavra como expressão da linguagem escrita, considera-se o princípio dialógico no processo de produção, num movimento de construção de sentidos e de interlocução, tanto por parte daquele que produz quanto daquele que realiza a leitura.

A reflexão dos excertos de poemas e prosas, aqui selecionados, tomados como indícios da relação escritor e o ato de escrever, possibilitou a classificação de uma relação demarcada por ações dialógicas caracterizadas por representações, identificadas como relação de complementariedade, em que a escrita se configura como uma ação que completa o escritor; relação de enamoramento, como uma ação que seduz o escritor ao ato de escrever, que possibilita uma proximidade e afetividade com o outro e consigo mesmo, por encontrar nas palavras a expressividade e relação de conflitos e embates, em que a escrita se torna ação desafiante, vista como trabalho de incansável busca, por isso atrai o escritor, ajuda-o a ir além de si mesmo, a superar limites da sua expressividade e criatividade.

Compreender o ato de produção escrita, requer pensar a língua como um conjunto enunciativo, balizado pela expressividade e por ações dialógicas em que o escritor é sujeito, leitor e autor, que atua com e sobre a palavra, como também é impactado por ela. Cada ato de escolha não se mostra desarticulado ou aleatório, mas antes meticulosamente pensado e planejado na determinação e escalação do léxico, da estrutura gramatical ou composicional, que constituirá a textualidade materializada na escrita.

A ação escritora se mostra uma prática interativa marcada pela interlocução constante com outras palavras, em relação oscilante, ambígua, intelectual, reflexiva, desejante e desafiante para o escritor. A interatividade acontece a princípio na busca de ideias e da forma de expressá-las, que requer ir além de si mesmo. Ao produzir sentidos, criam-se espaços abertos, diria Eco (2010), criam-se respostas livres, inventivas, dialógicas em lugares alhures, pois seu futuro será, segundo Sartre (2004, p.36), a página em branco, para em seguida, deparar-se com a materialidade da produção, deixá-la ir e reconhecer o não per- 
tencimento, pois “[...] para onde quer que se volte, o escritor só encontra o seu saber, a sua vontade, os seus projetos, em suma, a si mesmo; nada atinge além da sua própria subjetividade; o objeto por ele criado está fora do seu alcance, ele não o cria para si".

\section{REFERÊNCIAS}

AMORIM, Marilia. Cronotopo e exotopia. In: BRAIT, Beth. Bakhtin: outros conceitos-chave. 2. ed. São Paulo: Contexto, 2012.

ANDRADE, C. D. Poesia Completa. Rio de Janeiro: Nova Aguilar, 2008.

A relação entre oescritore aprodução escrita no viés da dialogicidade e interatividade

BAKHTIN, M. M. Estética da criação verbal. Trad. Paulo Bezerra. 4. ed. São Paulo: Martins Fontes, 2003.

. Marxismo e filosofia da linguagem. Problemas fundamentais do método sociológico na ciência da linguagem. Trad. Michel Lahud e Yara Frateschi Vieira. São Paulo: Hucitec, 2006.

Problemas da poética de Dostoiésvsk. Trad. Paulo Bezerra. 4. ed. Rio de Janeiro: Forense Universitária, 2008.

Para uma filosofia do ato responsável. Trad. Valdemir Miotello e Carlos Alberto Faraco. São Carlos: Pedro \& João Editores, 2010.

BARROS, M. Memórias inventadas - As Infâncias de Manoel de Barros. São Paulo: Planeta do Brasil, 2010.

BARTHES, Roland. o rumor da língua. Tradução Mario Laranjeira. 2. ed. São Paulo: Martins Fontes, 2004.

CERTEAU, Michel. A Invenção do Cotidiano: Artes de Fazer. 13. ed. Tradução de Ephraim Ferreira Alves. Petrópolis: Vozes, 2007. vol. I.

ECO, Umberto. Obra aberta: forma e indeterminação nas poéticas contemporâneas. 9. ed. São Paulo: Perspectiva, 2010. 
FALCÃO, Adriana. Pequeno dicionário de palavras ao vento. São Paulo: Editora Planeta, 2003.

FIORIN, José Luiz. Introdução ao pensamento de Bakhtin. São Paulo: Ática, 2006.

GOULART, Ilsa do Carmo Vieira. A palavra e seus "mistérios". Revista Linha Mestra, Campinas, n. 21, p. 401-407, ago./ dez., 2012.

Ilsa do Carmo

Vieira Goulart

GOULEMOT, J. M. Da leitura como produção de sentidos. In: CHARTIER, R. Práticas da leitura. Trad. Cristiane Nascimento. São Paulo: Estação da Liberdade, 2001.

LEMINSKI, Paulo. Melhores poemas de Paulo Leminski. Seleção de Fred Góes e Álvaro Martins. 6. ed. São Paulo: Global, 2002.

NERUDA, Pablo. Confesso que vivi - Memórias. Tradução Olga Savary. Rio de Janeiro: Difel, 1978. p. 51.

QUINTANA, Mario. Prosa e verso. 6. ed. São Paulo: Globo, 1989.

SARTRE, Jean-Paul. 0 que é literatura? Trad. Carlos Felipe Moisés. 3. ed. São Paulo: Ática, 2004.

STELLA, Paulo Rogério. Palavra. In: BRAIT, Beth. Bakhtin: conceitos-chave. 5. ed. São Paulo: Contexto, 2013.

VAL, Maria da Graça Costa; VIEIRA, Martha Lourenço. Língua, texto e interação: caderno do professor. Belo Horizonte: CEALE/ FaE/ UFMG, 2005. 